Amazonía Peruana, Volumen XVI, No 32, 2019; p.p 39-59

\title{
Milenarismo Tupí-Guaraní EN LA AMAZONÍA
}

\author{
Jaime Regan
}

\section{Resumen}

El artículo examina el mito amazónico de la Tierra Sin Mal y su vinculación a dos eventos extáticos entre la población tupí-guaraní (los urubúes del Brasil y los kokama y omagua del Perú). En el mito, un enviado de Dios anuncia un diluvio que debe destruir un mundo corrompido y crear un mundo nuevo, entregando a los sobrevivientes los elementos básicos de su cultura, para luego retirarse a su chacra. En un contexto de inundaciones especialmente destructivas, la visita del jesuita Samuel Fritz a los urubú en 1689 despertó un clima de movilización y confusa algarabía y, en un contexto similar, el brasileño José Francisco da Cruz, después de su arribo entre los kokama y omagua en el Perú, hacia 1976, formó una nueva iglesia reclamando que la gente «se aleje de toda maldad». En ambos casos, el personaje foráneo habría sido interpretado como el héroe mítico.

\section{Summary}

Two ecstatic events are examined in the light of the Amazonian myth of the Land without Evil, among the Tupí-Guaraní people, the Urubu of Brazil in 1689 and among the Kokamas and Omaguas of Peru beginning in 1976. In the myth an emissary of God announces a deluge that destroys an evil world and creates a new one giving the survivors the basic elements of culture, and then he withdraws to his farm. In the context of the severe damage caused by flooding, the visit of the Jesuit Samuel Fritz provoked an uproar among the Urubu; and the Brazilian Jose Francisco da Cruz, in the context of the similar severe damage caused by flooding, after his presence among the Kokamas and Omaguas in Peru, founded a new religion in which the people distance themselves from all evil. In both cases the stranger who arrived was considered the hero of the myth.

Palabras claves: Mito-milenarismo-Tupí Guaraní-Urubú-Kukama-Omagua 
En el año 1977 comencé la investigación sobre el movimiento milenarista tupí-guaraní en la Amazonía peruana (Regan 1977). Ahora, vuelvo a analizar los testimonios entonces recogidos, a partir de nuevos aportes bibliográficos y apreciaciones de informantes actuales.

El texto a continuación propone el estudio comparativo entre un acontecimiento ocurrido en el actual territorio amazónico de Brasil, en 1689, y el movimiento de la Santa Cruz en la región de Loreto, en Perú, a partir de 1969. En ambos casos, acontecieron unas inundaciones que sobrepasaron el ciclo normal del río y la presencia de un personaje foráneo con un discurso religioso interpretado por la población indígena como la deidad que anunciaba la destrucción del mundo.

Aunque las palabras de los relatos originales son las mismas, las perspectivas cambian. Las interpretaciones que desarrollé en la década de 1970 siguen siendo válidas pero se han acumulado nuevos conocimientos y experiencias que posibilitan una mayor profundidad en el análisis.

En la tradición cristiana existe el elemento milenarista, es decir, la esperanza de un reino de Jesucristo que dure mil años, la creencia en un paraíso espiritual nacida de una interpretación del capítulo 20 del libro del Apocalipsis (Alcañiz y Castellani 1962). En la historia de las religiones, el término "milenarismo" se ha apartado de su etimología "mil" y se ha usado para significar ideas de salvación o transformación en este mundo.

En la mitología de la familia lingüística tupí-guaraní, un dios destructor y creador está vinculado a una «Tierra sin mal», un paraíso terrenal donde las personas libres de maldad alcanzarán la salvación después de una futura destrucción del mundo, al tiempo que las chacras producirán sin siembra, continuamente y en abundancia (Nimuendajú 1978 y Métraux 1973). Según el especialista en milenarismo, Florentino Alcañiz (comunicación personal 1980), en momentos de grave crisis en una sociedad, surgen movimientos milenaristas donde los seguidores toman la visión de una sociedad ideal del pasado y la proyectan al futuro.

Existen estudios etnográficos, basados en testimonios de participantes de dos de estos movimientos de la familia etnolingüística tupí-guaraní: entre los guaraníes de Brasil en Nimuendajú (1978 [original 1914]); entre los tupí kokamas y omaguas (llamados kambebas en Brasil) del Perú en Regan (1983) y entre los kokamas en Agüero (1985).

Otros autores estudiaron la dimensión política de los movimientos tupíguaraníes: Alfred Métraux (1973), Egon Schaden (1974), Pierre Clastres (1974), Hélène Clastres (1978), Bartomeu Melià (1988) y Michael Brown (1994). Consideran estos movimientos como la expresión de la tensión entre modelos de liderazgo igualitario y jerárquico. Brown (ibid: 302i) incluyó el estudio del sincretismo de elementos indígenas y cristianos y Regan incluyó la dimensión ecológica (1983: 157-161). 
A pesar de una distancia de más de tres mil kilómetros entre los tupí-guaraní peruanos y los guaraníes, existen elementos comunes en su cosmovisión: mitos acerca de la destrucción y creación del mundo por una deidad, el mito de la «Tierra sin mal», el mito de los mellizos, la transmigración de almas y la reencarnación (Nimuendajú 1978: Schaden 1974; Melià 1988; Regan 1983).

\section{Mito Tupí Kokama y Omagua de la Tierra Sin Mal}

La versión más detallada del mito kokama de la Tierra Sin Mal es el testimonio ofrecido por la narradora kokama Lucía Ahuanari Pacaya (nacida en 1915), de la ciudad de Nauta (Regan 1983, I: 136-140). La idea kokama de la Tierra Sin Mal está vinculada a la destrucción de un mundo malo y la creación de uno nuevo. A continuación, se analizará este relato y las versiones parciales recogidas de otros testimonios de kokamas y omaguas.

\section{Destrucción}

La tierra desaparecía y volvía a aparecer porque la gente era pecadora. Era un castigo de Dios. Antes que desapareciera la tierra otra vez, apareció un gavilán pequeño a un hombre que hacía su canoa. El gavilán lo miró y se fue.

A un buen rato volvió a aparecer un joven de buena apariencia, que le preguntó al señor: “Qué estás haciendo?" El señor contestó: "Estoy haciendo mi canoa". El joven le dijo que no hiciera una canoa porque no le iba a servir porque uno de esos días iba a desaparecer la tierra. Dijo que hiciera más bien una balsa con su tambito, que metiera camotes, plátanos, papas, una jahua (fruta), su mujer y sus hijos. Desapareció el joven. Hizo caso al joven y comenzó a construir su balsa en medio de la plaza. La gente comenzaba a reír. Una vez terminada la balsa, metió las cosas, él, y su esposa y sus hijos.

Comenzó a manar agua desde debajo de la tierra por todas partes y se puso a llover. Se inundó toda la tierra y la balsa comenzó a flotar y moverse en las olas. Se hizo un mar. Pasaron tres meses cuando se iban terminando los víveres. Se les apareció el joven y le dijo al señor que tirase la jagua, y se fue. El señor hizo lo que mandó. La tiró para que cayera con fuerza. Cuando tocó el agua apareció la tierra (se secó el agua), y la balsa quedó sentada en una llanura de arena. Se veían colinas, montículos pequeños y grandes de arena. Las montañas arenosas son olas de mar transformadas.

\section{Creación}

No hubo agua por ninguna parte. Estaban desesperados porque casi no tenían agua ni alimentos. El joven volvió a aparecer y preguntó: “Qué necesidades tienen?" El señor contestó que no tenían qué comer, ni agua que beber. Tenían que beber de su orina. El joven cogió una flechita e hizo un círculo en la arena, sin ninguna explicación, y dijo que cavase allí. El joven desapareció. El señor le hizo caso y comenzaron a cavar y encontraron la sorpresa que había masa de yuca podrida. 
Tenían para comer, pero no para beber. Se apareció el joven llevando dos flechitas: una pequeña y otra grande y una balista (arco), y le dijo que con esta balista ballesteara con la flecha hasta donde cayera, primero con la grande y luego con la pequeña.

Una vez dadas las instrucciones, el joven se fue. El señor hizo lo que el joven había mandado. Cogió la flecha y la ballesta y lanzó la flecha hasta donde pudo, primero con la grande y luego con la pequeña. En cuanto las flechas tocaron la tierra manó agua. De la flecha grande salieron los ríos, y de la pequeña salieron las quebradas. De esta manera aparecieron las aguas.

Aparecieron una palomita y un cuervo. ${ }^{1}$

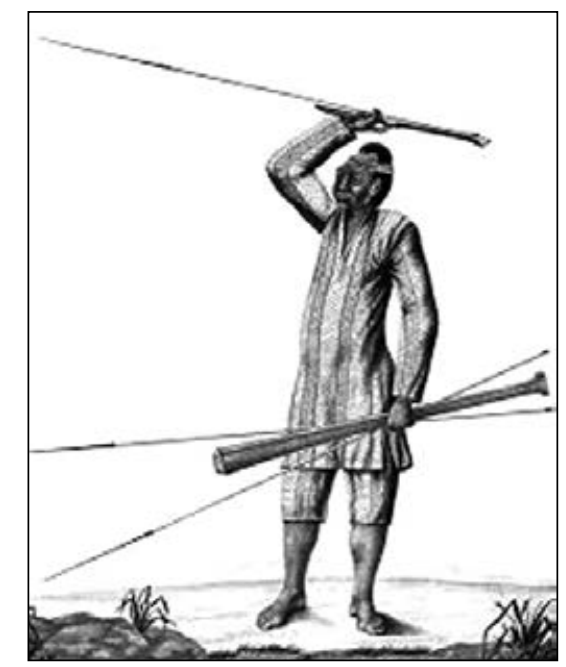

Índio Kambeba (Omagua o Kokama) con ballesta:

En: FERREIRA 1971, vol. I, prancha 117

\section{La Prueba a las dos hermanas}

Después de esto se encontraban sentados en su casa y se les apareció el joven, pero transformado en un mendigo con ropa sucia, rota, lleno de sarna, cara y cuerpo sucios. Le dijo a la mujer del señor que quería que su hija mayor le llevase al río para bañarle. La muchacha era bonita y por eso la escogió. La hija mayor se llamaba Magdalena y la menor se llamaba Dolores². Entonces la mamá le dijo a la hija lo que el viejo mendigo quería, y ésta se negó porque dijo que no quería bañarle a un viejo sarnoso. La madre la insistió pero ella se cerró, no quiso.

1 En la tradición mitológica europea las tres aves son el búho, la paloma y el cuervo (Murphy 2000: 83). Son las aves mensajeras que se comunican con la deidad.

2 Los nombres refieren a la Virgen de los Dolores, que aparece al lado de María Magdalena al pie de la cruz, según la descripción del Evangelio (Juan 19, 25). La versión abajo de Pedro Manuyama identifica al mendigo como Jesucristo. Estos tres personajes están representados en la imagen del Señor de los Milagros. 
Ante la negativa, la menor le dijo a su madre que quería bañar al viejo. Entonces la madre le dijo al viejo que la mayor no quería llevarle al río para bañarle, pero que la menor sí aceptaba la propuesta. Entonces la menor cogió al viejo y lo llevó al río. Lo sentó en la balsa y comenzó a bañarle. De la mugre del viejo que caía en las aguas, aparecieron diversas clases de peces, con escamas y sin escamas: por ejemplo la mojarra, la gamitana, curia piru, chiu chiu, y capitari. Terminado el baño los dos salieron contentos porque el viejo ya no era viejo sino un joven elegante. Él la tomó por mujer. La mayor que no quiso aceptarlo recibió como castigo una enfermedad llamada "overo", manchas blancas en el cuerpo y cara.

\section{Pruebas en las chacras}

Para gozar de la Tierra Sin Mal otras personas, igual a las hermanas, fueron sometidos a una prueba.

Desde aquel día la pareja caminaba por todas partes visitando a los vecinos en sus chacras y preguntando qué cosa querían sembrar en sus chacras. Cada uno decía lo que quería sembrar: plátano, camote, papa, maíz. Y todas estas cosas, al día siguiente de la petición, aparecieron sembradas en las chacras de manera espontánea, y los vecinos quedaban admirados porque no sabían de dónde habían aparecido (ibid., testimonio recogido en 1979).

\section{La prueba a las hermanas según otro informante}

Después del diluvio un hombre que tenía varias hijas mujeres se estaba bañando, cuando pasó por allí Jesucristo sucio, puro barro del diluvio. Entonces al pasar vio al hombre y sus hijas y pidió a la mayor que le quitara el barro que tenía, pero ésta que estaba nadando se negó y dijo: "Qué voy a bañar a ese hombre cochino". Entonces la menor se ofreció a bañarlo y Dios en premio la escogió como la Virgen y la subió al cielo. En castigo a la mayor que se negó, salió del agua negra con sarna. Desde ese día existe la sarna negra (Pedro Manuyama Fumachi, 31, kokama de Requena,1979) (Regan 1983, I: 163-164).

\section{La chacra de Diosito}

Una vez terminado de recorrer las chacras vecinas, ellos hicieron su chacra pequeña, en la cual sembraron maíz, camote, y semillas de yuca. Aquí es por primera vez donde apareció la semilla de la yuca tal como hoy en día se la ve en el tronco de la yuca. Una vez crecidas las plantas, comenzaron a cosechar. Muy de mañana se fueron a la chacra para coger el maíz, pero nunca se terminaba. Por más que cogían el maíz, permanecía igual. En vista de esto un día le preguntó la madre de la muchacha a su hija, "Qué es lo que hacían para no terminar de cosechar su maíz, si su maizal era chiquito que en un día se cosechaba todo". La muchacha dijo simplemente que el maizal no quería acabarse y permanecía igual (ibid.).

Según el antropólogo suizo Alfred Métraux (1973: 78), este lugar sería la "Tierra Sin Mal".

La mitología de algunas tribus tupí-guaraníes deja constancia de una tierra maravillosa llamada "tierra sin mal", a la cual el antepasado o el héroe civilizador se retiró después de haber 
creado el mundo y traído a los hombres los conocimientos esenciales para su supervivencia [...] y que en su proximidad se extienden los jardines maravillosos, donde siembras y cosechas se hacen sin esfuerzo. La Tierra Sin Mal no es solamente un lugar de delicias, es también el único refugio que quedará a los hombres cuando sobrevenga el fin del mundo.

Egon Schaden (1974: 161) también describe la idea guaraní de la tierra sin mal.

Os Guaraní imaginam a Terra sem Males como terra ideal, em que se realizan os desejos que neste mundo não são satisfeitos. (...) pregavam o retorno ás condiçöes de vida anteriores á vinda do homem branco. (...)

\section{Los acontecimientos en torno al jesuita P. Samuel Fritz a partir de 1689}

En el siglo diecisiete, el jesuita Samuel Fritz (1986 [1689]: 313) describió la fuerte inundación que padeció el río Amazonas.

A fines de enero del año 1689 (...) por febrero llegué a los Yurimaguas (...) Juzgaba así como otros años no se había anegado totalmente ese pueblo, estaría seguro de la creciente; pero fue tan grande este año de 89, que aun en lo más alto de la Aldea, a donde estaba el rancho en que yo moraba, había subido el río hasta una vara; y cuando comenzó el río a anegar las casas, vinieron con tanta fuerza las aguas hasta estar llena la creciente, que parecía ser bastantes para hacer andar una rueda de molina .

Durante esta inundación, que excedía por mucho lo usual, y después de pasar la boca del Río Negro y del Río Madeira, el padre Fritz se encontró con el cacique de la nación Tupinambarana que le dio un guía para llevarlo a la aldea Urubú (palabra tupí que significa "gallinazo negro" [Coragyps atratus]) 3,4 (ibid.: 316).

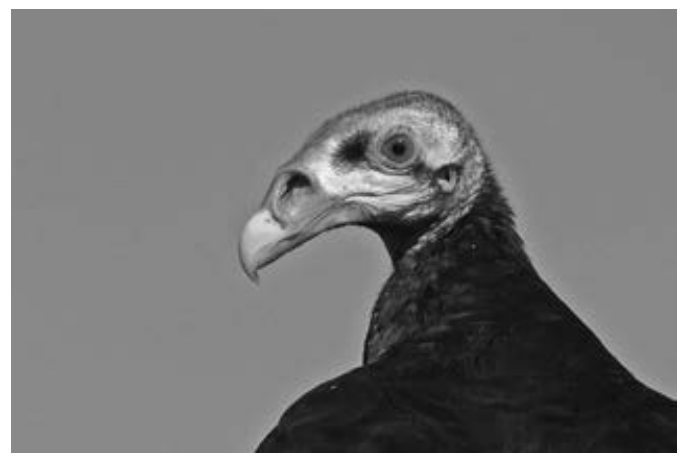

Gallinazo Cabeza Amarilla (subspecie urubutinga) (C) Bruno Rennó

3 En los idiomas kokama (Vallejos y Amías 2015: 232) y omagua (O'Hagan 2011: 27) se pronuncia "urupú".

$4 \quad$ El jesuita Cristóbal de Acuña (1986: 89) que pasó por esta región en 1640, menciona un grupo, los Urubutingas, el nombre de un urubú con cabeza amarillo-anaranjada. 


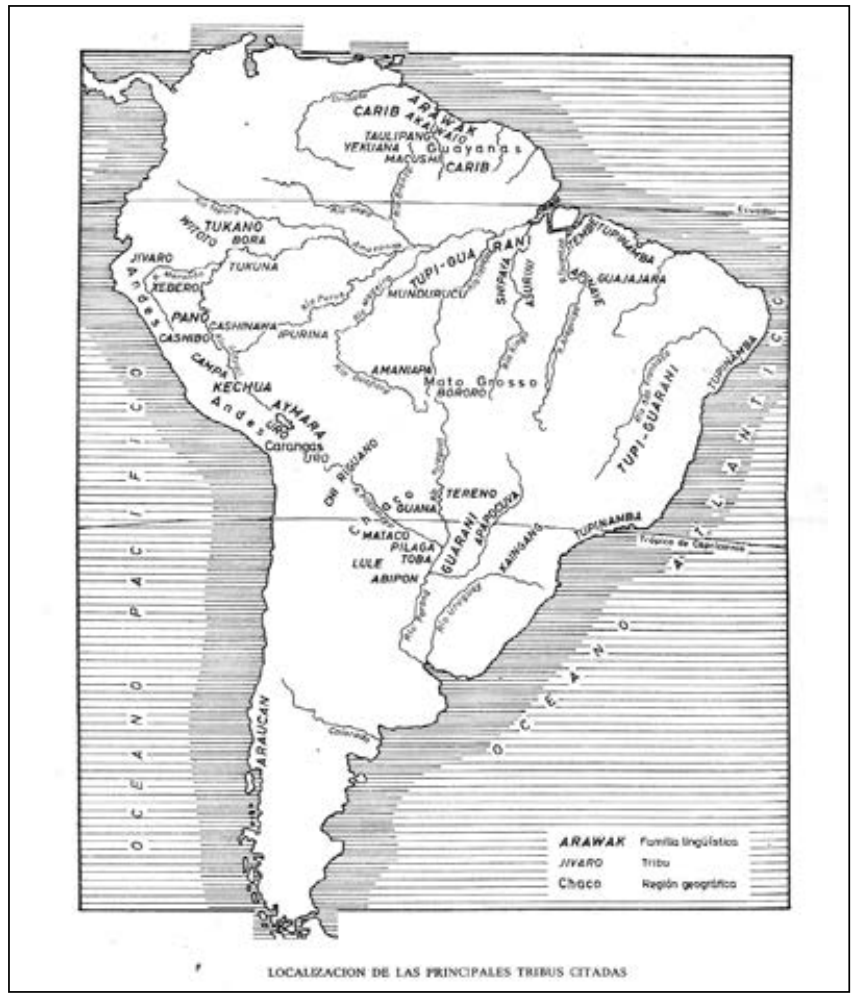

Mapa de Métraux (1973) que indica la ubicación de los Tupí-guaraníes en el bajo Amazonas.

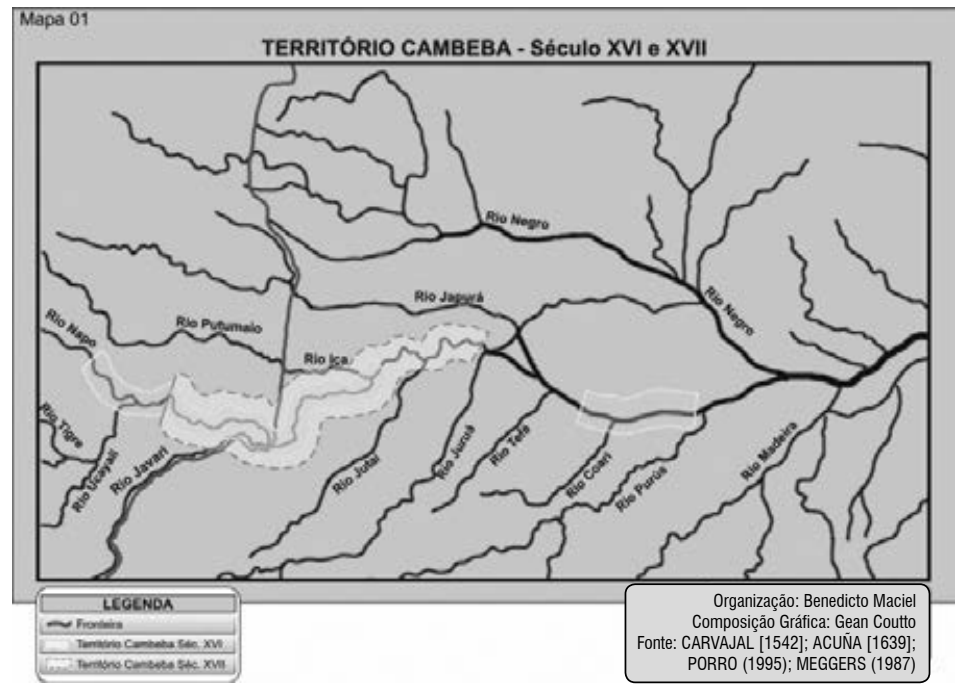


Cuando llegaron a este lugar, ya en territorio tupí, el padre describe lo que ocurrió: Es de reparar, que en mi bajada se levantó acerca de mí un alboroto grande, no sólo entre los gentiles comarcanos, sino que llegó hasta el Pará y San Luis del Marañón. Otro me decía santo e hijo de Dios, otros diablo Unos por la cruz que traía, decían que había venido un patriarca o un profeta, otros, un embajador de Persia; hasta los negros de Pará decían que había venido su libertador (ibid.: 317).

Los hechos claves son, en principio, la ocurrencia de inundaciones mucho más destructivas de lo normal y, en este contexto, la aparición de un extranjero itinerante que llevaba una cruz. Al llegar al pueblo tupí-guaraní de Urubú, se desató el tumulto. Según el testimonio de Fritz, algunos le decían santo e hijo de Dios y otros diablo. Según mitología de esta familia etnolingüística, el Dios es itinerante y es destructor y luego creador. Por eso, algunos le decían Dios y otros diablo.

El Padre Fritz fue detenido por los portugueses que lo pusieron bajo arresto domiciliario en el colegio jesuita de Pará durante diecinueve meses (ibid. 319).

En el viaje de regreso al Perú por el Amazonas, en 1690, el Padre Fritz fue testigo de los daños producidos por un terremoto. El misionero mercedario del río Urubú dijo que los indígenas atribuían el terremoto a la detención del P. Fritz en Pará.

Otra mentira anduvo en aquellos gentiles mientras estuve en Pará; que ya me habian hecho pedazos, pero que yo era inmortal; que luego mi alma hizo juntar los pedazos y entró otra vez en mi cuerpo. Con esas y otras muchísimas pataratas que unos Padres habían oído contar entre los indios, dicen, estaban todos alborotados, ya que no querían cosa de los portugueses, sino que los diesen al Padre. El P. fray Teodosio, para persuadir a sus indios que yo era hombre como los demás, mandó a algunos me tocasen las manos (ibid.: 322$){ }^{5}$

El Padre Fritz dejó una descripción de la destrucción.

Parecían ruinas de grandes ciudades; peñascos caídos; arboledas grosísimas desarraigadas y botadas al río; tierras muy altas con sus malezas encima caídas; (...) Decía Fr. Teodosio, que al mismo tiempo hubo mares horribles en el río y se murió muchísimo peje; y esto es lo que atribuían los gentiles a mi detención, diciendo que el Pará y todos habian de parecer (ibid.).

El padre Joao Felipe Bettendorf, superior jesuita, llegó a la aldea de Urubú, de tierra negra, situada en un acantilado sobre el río de los Urubús. En este lugar, colaboraba con los jesuitas el mercedario Frai Theodosio Freitas, quien le describió el hecho al padre Bettendorf.

5 Según el concepto kokama, cuando duerme y sueña una persona, su alma sale del cuerpo, pero el alma cuida el cuerpo desde afuera, y al despertar entra de nuevo en el cuerpo (Elías Curitima, kokama del Huallaga, comunicación personal, 1983). 
Houve poucos mezes antes um terrivel terremoto por aquellas bandas, e tal que me contou o Padre Theodosio quem andando elle por aquelle tempo pelo rio da Amazonas, de repente se amotinaram as aguas (Bettendorf 1910: 492).

(...) diziam uns indios do rio Urubú que o rio trasbordara de tal sorte que subvertera uma aldêa, mas isto achei em ser falso (...) (ibid: 493-4).

Dicen los kokamas que, en el diluvio, lo que estaba en la superficie de la tierra, se volteó hacia abajo y se quedó en el fondo del río, donde ahora hay ciudades debajo del agua pobladas de gente.

El fraile habla de los chamanes llamados pagés que dijeron que los indios se convertirían en blancos y los blancos en indios.

Ha por aquellas partes grandes feiticeiros a que chaman pagés; estes diziam, conforme me referia o reverendo frei Theodosio, que os indios se haviam de converter em brancos e os brancos em indios, mas parando tudo em nada (...) (ibid.).

En una versión del mito kokama del diluvio una chica bonita se convirtió en fea y la fea en bonita. Los tupí-guaraní conciben el diluvio como un tiempo, no solo de destrucción, sino de la transformación de las personas y las cosas en lo opuesto.

\section{Los Urubú Ka'apor}

Se supone que los actuales Urubú Ka'apor (Urubús del bosque) son descendientes de los Urubú que conocieron los padres Fritz y Bettendorf. "El pueblo principal con la casa del misionero e iglesia estaban situados en un acantilado de tierra negra a cuyo pie corre el bello río Urubu" (Bettendorf (1910: 492). El actual grupo se autodenomina Urubú Ka'apor (Urubú del bosque) después de su probable migración del lugar ribereño de los Urubú de los siglos anteriores.

Un dato de enlace con el siglo XX es la observación del padre jesuita Cristóbal de Acuña (1986: 89) en 1639 en un viaje por el Amazonas dice los "Urubutingas que son muy curiosos en labrar cosas de madera". Hacia 1900 los primeros colonos que conocían a los Urubú Ka'apor decían que tenían baúles fabricados de cedro.

Los Ka'apor surgieron como un pueblo distintivo hace casi 300 años, probablemente en la región ubicada entre los ríos Tocantins y Xingu. Quizás por la ocurrencia de algunos conflictos con los colonizadores luso-brasileños así como con los pueblos nativos, iniciaron una larga y lenta migración que los llevó, a fines de 1870, desde el actual estado de Pará, a través del río Gurupi, hasta el actual estado de Maranhão. Los colonizadores brasileños que atacaron y aniquilaron a los habitantes de las aldeas Ka'apor, hacia el año 1900, se sorprendieron al descubrir los espléndidos tocados de coloridas plumas que guardaban dentro de baúles de cedro dado que los sobrevivientes del ataque, al darse a la fuga, dejaron abandonados (Balée, 2017). 
El antropólogo brasileño Darcy Ribeiro (1992: 162) en 1951 encontró el caso de un urubú que se suicidó debido a que un paje tembé, grupo tupí-guaraní vecino, le había convencido que un avión comercial que sobrevolaba la comunidad todas las semanas iba enviar una lluvia de fuego. En otra aldea de los urubúes destruyeron sus casas y sus posesiones más apreciadas, los adornos plumarios, porque los pajés tembé profetizaron el fin del mundo por una explosión del sol.

También entre los kokamas y omaguas se habla de una destrucción del mundo con fuego.

El fin del mundo no va a ser de agua, sino candela. Por eso tienen que irse de aquí y buscar su Tierra Santa donde van a hacer sus chacras. Justo la están haciendo arriba en Nanay (Odilia Ruiz de Durán 46, Pueblo Joven Santa Rosa, Iquitos, informante kokama 1981).

El fin del mundo, cuando venga ahora, no será con agua. Será con fuego y azufre ardiendo, que caerá del cielo para quemar todos los pecadores. Será cosa terrible y nunca vista. Sólo la Santa Cruz salvará a los que la llevan y sean buenos (Marcelino Huani Gonzales, 55, Pueblo Joven Santa Rosa, Iquitos, informante omagua, 1981).

Tanto los kokamas y omaguas como los urubús comparten la visión apocalíptica de la tradición tupí-guaraní.

\section{El Movimiento milenarista entre los Kokamas y Omaguas a partir de 1971}

En 1969 el visionario José Francisco da Cruz (José Nogueira), nacido en Minas Gerais, Brasil, tuvo una serie de visiones de Jesucristo que le envió a predicar la devoción a la Cruz, organizando a la gente en hermandades. La presencia del «hermano José» en Loreto despertó la curiosidad de la población mestiza en general, pero su convocatoria mermó rápidamente después de su salida del país en 1972. Sin embargo, se formó una nueva iglesia integrada por los pobladores más pobres y marginados de las localidades loretanas cuyo núcleo eran los kokamas y omaguas, de la familia etnolingüística tupí-guaraní.

El fundador se asentó luego en Brasil, entre la población tikuna (Oro 1989). Desde allí enviaba mensajes a sus seguidores en el Perú, donde se formaron comunidades religiosas y se establecieron cargos y juntas directivas, las que se ocupaban de las actividades litúrgicas y la disciplina. Además, desde Brasil, se formaron sacerdotes itinerantes que visitaban las comunidades para animar la fe de los seguidores.

La llegada a la región amazónica del Perú de este personaje coincidió con una serie de inundaciones especialmente destructivas. El movimiento, llamado Hermandad de la Cruz u Orden Cruzada, puso énfasis en el aislamiento de los pueblos «donde existía la maldad». Se formaron así comunidades donde se plantaba una enorme cruz de madera. Los rituales practicados por los devotos incluían la 
veneración de la Cruz, estudio de la Biblia y la entonación de canciones cristianas cuyos temas se asociasen a la Cruz de Cristo (véase Brown 1994).

La Orden tiene elementos doctrinales y prácticas tomadas del catolicismo y el evangelismo, con un fuerte sustrato de la cosmovisión tupí-guaraní, la búsqueda de la Tierra Sin Mal y la interpretación de los sueños (Regan 1983, II: 157).

A fines de 1976 los miembros de las comunidades iniciaron la búsqueda de la "Tierra Santa". En este afán, un grupo de hermanos del Bajo Ucayali, surcaron el río Blanco, guiados por un niño profeta que pronunciaba citas bíblicas (Regan 1983, II: 150) En otros lugares, los hermanos, convencidos del mensaje profético, abandonaron sus pueblos para formar comunidades en lugares apartados, a fin de liberarse de las malas costumbres de la gente, «retirarse del mundo» y esperar el tiempo de la destrucción.

Según los dirigentes, el hermano José les ordenó formar un pueblo en un lugar apartado. En noviembre de 1977 el patriarca Juan Evangelista del Espíritu Santo viajó al alto río Pisqui con 33 hombres (uno para cada año de vida de Jesucristo) con unas mujeres de cocineras. Pronto se difundió la noticia que se había encontrado la Tierra Santa, y la expedición iba creciendo en número. Llegaron unas cien familias, entre ellos muchos Cocamas y Omaguas. La comisión original tenía la intención de preparar las chacras y luego traer más gente, teniendo asegurada la alimentación (ibid.).

Sin embargo, el entusiasmo de tantas personas que querían «salvarse de la destrucción del mundo» frustró la posibilidad de fundar la Nueva Jerusalén en la tierra santa de Palestina. Se acabaron los alimentos y muchos se enfermaron. Algunos de los hermanos se quedaron en la región trabajando para los patrones de la zona, y muchos otros regresaron sus lugares de origen. Una niña profetisa citaba pasajes de la Biblia y proclamaba que sufrían porque habían abandonado las cruces en sus comunidades (ibid.: 150-151). Encontraron también que algunos de los dirigentes no cumplían todos los estatutos establecidos por el hermano José y se aprovechaban de los demás.

Un grupo de hermanos quería separarse para formar una comunidad purificada compuesta solo de «hermanos buenos» (Regan 1983, I: 152-153).

Los de 9 de Octubre (Iquitos), se trasladaron a Manatí a hacer sus chacras para servirse en grupo y esperar el fin del mundo. También los de Bagazán van a salir porque tienen que buscar la Tierra Santa, que tiene que ser altura y bien lejos, así los manda el hermano, ya que van a venir tiempos de hambruna. Dicen que de cualquier gente no crecerán sus sembríos, de ellos sí. El hermano mandó salirse, llevarse su cruz a la Tierra Santa, lugar central y virgen, donde nadie ha pisado, que va a venir una alagación grande que tapará todo y no dejará nada. Hasta fin de año ya deben pensar en abandonar el lugar para ir en busca de la tierra santa. Como dice la Biblia: "Abandona tu casa, padres, y ven a la tierra que yo te mostraré". Por eso 
muchos están abandonando sus hogares, sean solteros o casados, para cumplir esa orden del hermano (Odilia Ruiz de Durán, 46, Pueblo Joven Santa Rosa, Iquitos, 1981).

Se han trasladado en su mayoría a otro lugar para vivir muy aparte, porque dicen que ellos no pueden estar metidos con los incrédulos (José Noteno, 50, Ana Papa Rayo, 18, Pascuala Coquinche, 80, Monterrico, 1981).

Los grupos no se han trasladado a otro lugar. Unos pocos piensan en llegar a una tierra santa. Es un engaño. Ellos tienen miedo de la inundación (Agustín Flores Tello, 56, Caserío Buena Vista, 1981).

Algunas familias han ido al río Manatí, otras por la quebrada Pichuno, río Pisqui, por el río Tapiche, Marañón y bajo Amazonas en busca de nuevas tierras con la finalidad de hacerlos producir y crear un ambiente netamente cristiano (Carotith Isuiza Flores, Belén, Iquitos, 1981).

En la comunidad de San Joaquín de Omaguas, un grupo de hermanos crucistas formó un anexo separado, a 500 metros de distancia, llamado Buena Unión, a fin de alejarse del resto de la comunidad donde, entendían que existía maldad (comunicación personal del teniente gobernador en 1980).

Estos casos y el de los hermanos que esperaban lograr la salvación por el mero hecho de llegar a la Tierra Santa en el río Pisqui, muestran que algunos no habían captado todo el sentido de la Tierra sin Mal. Los hermanos más sabios se dieron cuenta de los elementos fundamentales. Para lograr la salvación y disfrutar el Paraíso, había que trabajar en la agricultura y actuar sin malicia. Lo que más motiva a la gente, a salir a buscar la Tierra Santa, es la idea de la cercanía del fin del mundo. La Biblia dice que el mundo se destruirá con fuego, pero se conserva la idea de la destrucción del mundo, relacionada con el agua por una inundación (Regan1983, I: 154).

El fin del mundo no va a ser de agua, sino de candela. Por eso tienen que irse de aquí y buscar su Tierra Santa donde van a hacer sus chacras. Justo la están haciendo arriba en Nanay (Odilia Ruiz de Durán, 46, Pueblo Joven Santa Rosa, Iquitos, 1981).

El fin del mundo, cuando venga ahora, no será con agua. Será con fuego y azufre ardiendo, que caerá del cielo para quemar a todos los pecadores. Pero antes, habrá grandes guerras en todas las naciones. Será cosa terrible y nunca vista. Sólo la Santa Cruz salvará a los que la lleven y sean buenos. La cruz es semejante al arca del patriarca Noé. Es el único medio de poder escapar a este terrible desastre, ya que en este tiempo habrá grandes crecidas de todos los ríos, malogrando todo (Marcelino Huani Gonzales, 55, Pueblo Joven Santa Rosa, Iquitos, informante omagua, 1981).

Estos movimientos religiosos tienen características comunes: la esperanza de un paraíso terrestre y un héroe que trae salvación. En este sentido, el historiador de religiones Vittorio Lanternari escribió: 
El ambiente religioso es oficialmente el católico; no obstante, en estos movimientos no es difícil reconocer una estrecha continuidad histórica, con los movimientos indios de épocas anteriores; mejor dicho, es fácil apreciar en ellos una analogía de temas fundamentales, especialmente el tema de la tierra prometida, o paraíso terrestre de inminente realización, y el tema del héroe o mesías que regresa trayendo salvación y libertad (Lanternari 1965: 221).

La Orden Cruzada Católica Apostólica y Evangélica se basa en la creencia de la llegada de Jesucristo, o por lo menos de un enviado de Dios y, dentro de la Orden, hay un sector que conserva plenamente la tradición tupí-guaraní de la Tierra sin Mal.

Desde la primera llegada de los europeos a América los indígenas mostraron su resistencia. Entre los tupí-guaraní de Brasil y Paraguay, surgieron líderes religiosos indígenas que anunciaban la inminente destrucción del mundo y conducían a sus seguidores en la búsqueda de la Tierra sin Mal (Pereira 1969: 191-196).

El arqueólogo brasileño José Proenza Brochado (1989: 80-81) planteó una hipótesis plausible. Señala que, en el siglo XVI, los pueblos tupí-guaraníes del Amazonas estaban en plena expansión en busca de tierras nuevas todavía no cultivadas. Las connotaciones sobrenaturales $\mathrm{Y}$ mesiánicas serían posteriores, cuando esta búsqueda fue impedida por la conquista europea.

\section{La Tierra Sin Mal amazónica}

La Tierra sin Mal no sólo es lugar, sino que también es un estado que se alcanza por medio de una actitud. Cuando Diosito o el héroe cultural caminaba por las chacras, los deseos de las personas buenas se convertían en realidad. Pero, los que expresaban pensamientos malos, no lograban participar del paraíso. Cuando estos cocamas y otros pensaban que era inminente la venida del diluvio por las crecientes fuertes del río, a causa de la ambición, el odio y la corrupción en el mundo, se separaron de las «personas malas» para buscar un lugar dónde no haya maldad. Así, el mito da un modelo de comportamiento para las épocas de crisis en el mundo.

La Tierra sin Mal no solo es un fenómeno del pasado sino que se hace vigente cuando se piensa que se aproxima el fin del mundo. Si la gente cree que es inminente la destrucción o sea, que hay maldad en el mundo, entonces los acontecimientos del tiempo mítico se trasladan al presente o al futuro inmediato.

Las pruebas en las chacras

El segmento del mito de la Tierra sin mal sobre las pruebas en las chacras está difundido por toda la región Loreto y Ucayali, no solo entre los tupís, sino también entre los quichuas del Napo y los mestizos en general (Regan 1983, I: 141-142).

(Después del diluvio) se sintió que la balsa bajó a tierra, y en tal se secó y se bajó a tierra nueva, el día claro, la tierra brillante, y otro mundo nuevo. Trabajaban en un mundo 
nuevo y hacían sus chacras y se preguntaban ellos: “¿Qué vas a plantar, yuca?" Y el poder de Dios hacía aparecer yuca. Este hombre que no conocían les preguntaba: “Qué vas a plantar, plátanos?" Plátanos aparecían y así amanecían. Así iba caminando este hombre que era Dios. Llegó a una persona mala y le preguntó: "¿Qué vas a plantar?" "Yo voy a sembrar piedras", y piedras cosechó. Se preguntaban: “QQuién era? ¿Será Dios?" (Alfonso Amía Ahuanari, 41, Indiana, versión cocama 1981).

Andaba un ancianito por las selvas y por las chacras, mirando los trabajos de la gente. Muchos no reconocieron a Dios; se había convertido en un viejito carachoso. El andaba probando a la gente en la chacra. "¿Qué vas a sembrar?" preguntó a uno. Este era un hombre malvado, se molestó: "¿Qué crees que voy a sembrar? Pues sembraré maraña con espina". "Mañana verás", dijo Dios y se fue. Al día siguiente, cuando el hombre miró, su chacra era un bosque de maraña y espinas (...).

Pero hubo gente que le contestó con respeto. "¿Qué piensas sembrar, hijo?" "Quiero sembrar yuca, plátano, piña, maíz, y toda clase de plantas". "Está bien, hijo. Piensa en Dios y mañana verás". A la mañana se fue a ver: en su chacra, Dios con su poder, había hecho crecer todo. El plátano, el maíz, todo estaba listo para cosechar. "Era Dios Yaya"', pensó el hombre y se convirtió en gente de Dios, se hizo "santo" (versión quichua del Napo, Mercier 1979: 19-21).

Se aparecía el Padre Eterno en cualquier trabajo. Para ver cómo eran los hombres, se les pedía hospedaje y si no le daba, en el momento se quemaba. También si no le contestaban bien en qué sembraban o qué hacían, les castigaba secando sus tierras o produciendo espinas o piedras (José Rioja Dahua, 53, Indiana, 1981).

Antiguamente había un viejito que caminaba por todo el mundo preguntando a la gente qué quisiera sembrar. La gente buena le decía que querían algo de comer. Entonces a ellos el viejito les decía que al día siguiente tendrían arroz unos, maíz otros, y así sucesivamente. Y verdad que al día siguiente aparecían grandes maizales y yucales en las chacras de la gente buena. Cuando la gente mala le contestaba que querían piedras, al día siguiente hasta en su patio amanecían las piedras (José Huayta, 60, Yarinacocha, 1981).

Un señor estaba sembrando en su chacrita palo de yuca y maíz. En eso se le presentó un señor y le preguntó qué hacía. Le respondió que estaba enterrando las estacas de yuca para ver si crecía. Entonces el señor le dijo: "Yuca siembras, yuca cosecharás". A un rato se dio cuenta que todo había crecido. Otro le respondió amargo al mismo personaje: "Aquí estoy enterrando piedras, qué tienes que venir a preguntarme nada". A éste le contestó: "Si piedras siembras, piedras cosecharás". A las pocas horas el campo se llenó de piedras. A otro que le contestó de mala manera también le llenó la chacra de yerba. Este señor era el mismo Dios.

Dios caminando encontró a una viejecita bien pobrecita a la que dijo que dentro de poco tendría su buena casa y muchos animales. Al poco tiempo aparecieron las gallinas como si fueran gallinazos. Una señora estaba llorando junto a sus hijitos porque no podían comer, ya no tenían con qué hacer su candela y asar su pescado. En eso se acercó Dios en la forma 
de un anciano y le dijo que no llorase porque él tenía lo necesario para el fuego, y extrayendo de su bolsillo dos piedras, las frotó haciendo la candela para la señora y sus hijitos (Vasilia Trujillo Padilla, 56, San Isidro, Ucayali 1981).

Antes Dios se aparecía en diferentes lugares como un viejito bien sisurro (con una plaga llamada siso), y la gente le odiaba porque le veían así. Una vez se apareció a una señora y le preguntó qué estaba sembrando, y la mujer le contestó que estaba sembrando yuca y plátano, entonces le dijo: "Después de tres días vuelve a tu chacra", y fue la señora otra vez y encontró yuca, plátano bastante maduro, y al ver esto la señora agradeció a este señor (Vilda Alván, 40, Prolongación Sargento Lores, Iquitos 1981).

Dios visitó la tierra antiguamente en forma de un perro sisurrito. Entraba a las casas con hambre. En algunas casas le recibían y le daban de comer. En otras casas le golpeaban con palo y le insultaban. Dios hizo así para ver quiénes eran buenos y quiénes eran malos. Después vino en forma de un joven predicando a la gente su Evangelio (Flor de María Grández, 65, Belén, Iquitos 1981).

Dios visitó a los hombres disfrazado de mendigo y notó que la gente en su mayoría no hace caso a los pobres (Fulton Pinchi Chota, 37, Bagazán, Iquitos 1981).

Para muchos se aproxima el fin del mundo. El mundo mismo se va a destruir, matándose los hombres entre ellos. Ya el hombre no va a querer trabajar y para vivir tendrá que robar a su hermano. Muchos hombres ya no creerán en Dios. Jesús estará paseando por los ríos y los campos conversando íntimamente con la gente. Uno dirá: "¿Qué haces tú paseando por aquí? Esta tierra es maldita, no da nada, ¿por qué tengo que sudar todo el día para cosechar piedra no más?". Y de mala gana botará a Jesús de su tierra, y amanecerá la chacra de esos llena de cascajo. Al otro que le saluda y dice bien: "Yo trabajo mucho pero la tierra me da para mi familia y para ayudar a mis hermanos que sufren". Ese hombre será bendecido y Jesús le dará muchos frutos, pesca, caza, etc. (Leonidas Silvano Tamani, 40, Nauta, informante kokama 1981).

\section{Factores ecológicos}

La cosmovisión da las características específicas al movimiento religioso, pero hay otros factores más inmediatos que actúan, entre los que destaca la ecología, sobre todo el ciclo de las crecientes y vaciantes. El mito cocama de la destrucción del mundo anterior, y la creación de un mundo nuevo describe este proceso. Un desequilibrio en el orden moral produce un desequilibrio en la naturaleza. La creciente rebasa sus límites causando una inundación que cubre toda la tierra. Luego el ciclo pasa al otro extremo rebasando los límites de la vaciante, y se secó la tierra. No había que beber. Finalmente el héroe civilizador con su ballesta dispara las flechas para crear los ríos, restableciendo el equilibrio natural.

Los casos de 1689 y 1969 tienen en común inundaciones más elevadas que el nivel normal de la creciente. Puede ser el resultado de un terremoto como el caso de 
1689 o sostenida como lo que ocurrió a partir de 1969. En algunos casos se debe a fluctuaciones en la llegada o intensidad de la estación lluviosa.

Cuando las lluvias del sur persisten demasiado o las del norte se inician temprano (...) se inunda la tierra que por lo general está por arriba del nivel normal de creciente. Cuatro veces durante la primera mitad de este siglo (veinte) han ocurrido graves dislocaciones del régimen "normal" de las lluvias. Aunque la creciente de 1953 sólo alcanzó 2.8 m. por encima del promedio, tuvo un efecto desastroso en las cosechas y el ganado (Meggers 1976: 26).

En 1969 los factores importantes fueron los desmontes en la selva alta para la carretera marginal y en la selva baja para la exploración petrolera (véase Regan 1983, II: 159-161). En ambos casos apareció un personaje religioso que, para la gente, correspondía al dios destructor del mito tupí-guaraní.

Durante los años de las crecientes fuertes, muchos agricultores sufrieron la destrucción de sus chacras. Emigraron a centros urbanos, sobre todo Iquitos, en busca de trabajo, y no lo encontraron. La Orden está constituida, además de agricultores, por desocupados y obreros eventuales. También por estos años muchos jóvenes abandonaron el campo para trabajar en las compañías petroleras, con lo que bajó la producción de alimentos y aumentaron los precios en los poblados loretanos.

En los centros urbanos, la gente se encontraba pobre, se iban perdiendo los valores tradicionales de ayuda mutua, y aumentó el egoísmo. Los hermanos señalaron como una de las causas principales de todos sus males el haber dejado de practicar la agricultura. El cambio de esta orientación religiosa produjo un éxodo al campo y una vuelta al trabajo agrícola. Muchos hermanos dicen: En el fin del mundo van a faltar alimentos o piensan que para salvarse hay que practicar las labores del campo, sobre todo en tierras de altura.

Entre marzo y mayo de 1982 se dio en la selva una de las más fuertes inundaciones que recuerdan los pobladores de la zona. La mayoría de los agricultores sufrieron pérdidas en los sembríos de bajial. Sin embargo muchos de los Hermanos de la Cruz se salvaron de los efectos de la creciente por haber hecho pequeñas fundaciones en las cabeceras de los ríos. Con ello, ante la opinión común, se hicieron realidad las predicciones. Pero, la mayoría que siguió viviendo en sus propios caseríos, la sintieron y sufrieron como todos los demás ribereños.

La posición subalterna de los hermanos dentro de la estructura económica y social se representa en el discurso tradicional tupí como "la maldad" y la búsqueda de la "Tierra sin maldad" es la propuesta de salida de esta situación (Agüero 1988: 9). Los hermanos no usan la expresión "tierra sin mal" sino "villa" o "Nuevo Jerusalén", aunque un requisito para pertenecer es de estar sin maldad. 


\section{Personajes}

Dos tipos de personaje religioso se destacan en estos relatos: el héroe cultural y los curanderos itinerantes. Aparece un héroe cultural o divinidad en el mito para anunciar la destrucción del mundo. Para los urubúes de Brasil era el padre Fritz y entre los kokamas y omaguas del Perú es el hermano José Francisco, considerado por muchos una reencarnación de Jesucristo. Otro personaje son los karaíes, chamanes itinerantes que viven en la periferia de las comunidades de la tradición tupí-guaraní. En la región de Nauta y Requena los llaman santos vivos.

El fray Theodosio los llama feiticeiros pagés entre los Urubú del siglo XVII. La palabra para "chamán" en kokama es "payun" (Vallejos y Amias 2015: 155). Según la antropóloga loretana Roxani Rivas (2011: 445), la palabra kokama payun corresponde al pajé del portugués. La "y" en kokama suena más como la "j" en portugués. Algunos kokamas escriben "padsun" que se acerca más a la pronunciación portuguesa.

Agüero (1994: 158-159) parece fusionar los conceptos de héroe cultural y karaí. Sin embargo, Métraux (1973: 6) se acerca más a la realidad peruana. Dice que, en el proceso de la evangelización de los tupí-guaraníes, Cristo fue asimilado al héroe cultural y los santos a los chamanes.

En la Iglesia Cruzada es el presidente de la comunidad quien representa a la agrupación religiosa y preside las liturgias que forman parte de la estructura del movimiento. Los personajes carismáticos son el fundador José Francisco da Cruz, el héroe cultural, y los sacerdotes itinerantes que visitan los grupos locales para animarlos y cumple un papel comparable al del karaí.

\section{Mitificación de Procesos Históricos}

Mircea Eliade, en su libro el Mito del Eterno Retorno (1979) propone que el tema que domina en todo pueblo arcaico es la tendencia de abolir la historia y retornar al punto más allá del tiempo cuando comenzó el mundo (véase Pals 1996: 179).

Operan en estos acontecimientos unos hechos históricos y un proceso de mitificación. Explica cómo funciona la memoria popular, que transforma el personaje histórico en arquetipo y los hechos se transforman en acciones míticas.

(...) la memoria popular retiene difícilmente acontecimientos "individuales" y figuras "auténticas". Funciona por medio de estructuras diferentes; categorías en lugar de acontecimientos, arquetipos en vez de personajes históricos. El personaje histórico es asimilado a su modelo mítico (héroe, etc.), mientras que el acontecimiento se incluye en la categoría de acciones míticas (Eliade 1979: 48 y 130). 
Habla del carácter no histórico de la memoria popular,

...la impotencia de la memoria colectiva para retener los acontecimientos y las individualidades históricas sin transformarlos en arquetipos, es decir, sin anular todas sus particularidades "históricas" y "personales" (...) (ibid. 51).

Así, Samuel Fritz y José Francisco da Cruz asumen el papel de héroe cultural durante las inundaciones excesivas, que son el preludio de la destrucción del mundo.

La tradición mítica indígena, al entrar en contacto con el cristianismo, no sufre «pérdida» y tampoco rechaza lo nuevo. Una característica de las culturas indígenas es la inclusión o sincretismo religioso. El antropólogo Michael Brown (1994: 299) considera al cristianismo como un aliado que, por medio de la inclusión, ayuda a mantener la cultura indígena, mediante una integración de símbolos y conceptos.

Brown critica el pesimismo y visión romántica de Pierre Clastres (1987: 160-161) que lamenta "la creación de un sincretismo empobrecedor donde, bajo la máscara de un Cristianismo siempre superficial, el pensamiento indígena busca sólo posponer su desaparición". Para Brown los movimientos indígenas milenaristas son "esfuerzos vigorosos de respuesta frente al control de los blancos sobre el cristianismo" (ibid.).

\section{$\underline{\text { Comentario }}$}

Se presentaron dos acontecimientos amazónicos entre pueblos de la cultura tupí-guaraní que reaccionaron de manera similar frente a desastres de la naturaleza, interpretados como señales de la inminente destrucción del mundo. Los urubúes de los siglos XVII y XX fueron instigados por los "pajés" a reaccionar desde su visión apocalíptica del mundo. Los kokamas y omaguas reaccionaron del mismo modo. En el caso peruano del siglo XX, donde hay más información, el pueblo encuentra en su tradición una alternativa para rehacer sus vidas en el camino a la construcción de un mundo sin maldad. 


\section{Bibliografía}

Acuña, Cristóbal

1986 "Descubrimiento del Amazonas". En: Informes de Jesuitas en el Amazonas. Iquitos: IIAP-CETA. [original 1639].

Agüero, Oscar

1985 “El Milenio en la Amazonía Peruana". En: Amazonía Peruana 12: 133-145. Lima: CAAAP.

Alcañiz, Florentino y Leonardo Castellani

1962 La Iglesia patrística y la parusía. Madrid: Ediciones Paulinas.

Balée, William

2017 Cultural Forests of the Amazon. Tuscaloosa: The University of Alabama Press.

Bettendorf, Joâo

1910 "Chronica da Missâo dos Padres da Companhia de Jesus no Estado do Maranhao". En:Revista do Instituto Histórico e Geográfico Brasileiro, vol. 72 (1): 1-697. Rio de Janeiro [original 1698]

Brochado, José

2017 “A Expansão Policrómica Amazónica”. En; Dédalo 27: 65-82. São Paolo, 1989.

Brown, Michael

1994 "Beyond Resistance: Comparative Study of Utopian Renewal in Amazonia". En: Amazonian Indians from Prehistory to the Present. Tucson: The University of Arizona Press.

Clastres, Hélène

1978 Terra sem mal o profetismo tupi-guarani. São Paulo: Editora Brasiliense.

Clastres, Pierre

1974 La société contre l'etat. París: Minuit.

Eliade, Mircea

1979 El Mito del Eterno Retorno. Madrid: Alianza Editorial, .

Ferreira, Alexandre Rodrigues

1971 Viagem filosófica pelas capitanias do Grão Pará, Rio Negro, Mato Grosso e Cuiabá 1783-1792. (iconografia, vol. I: Geografia e Antropologia). Rio de Janeiro: Conselho Federal de Cultura. 
Graziano, Frank

1999 The Millenial New World. New York: Oxford University Press.

Lanternari, Vittorio

1961 Movimientos Religiosos de Libertad y Salvación en los Pueblos Oprimidos. Barcelona: Editorial Seix Barral.

Meliá, Bartomeu

1988 Nande Reko, Nuestro Modo de Ser. La Paz: CIPCA.

Mercier, Juan Marcos

1979 Nosotros los Napuruna, Napu Runapa Rimay: Mitos e Historia. Iquitos: Publicaciones CETA.

Métraux, Alfred

1973 Religión y Magias Indígenas de América del Sur. Madrid: Editorial Aguilar.

Murphy, G. Ronald

2000 The Owl, the Raven and the Dove: The Religious Meaning of the Grimms' Magic Fairy Tales. Oxford University Press.

Nimuendajú-Unkel, Kurt

1978 Los Mitos de Creación y de Destrucción del Mundo. Lima: CAAAP.

O'Hagan, Zachary

2011 Diccionario del Idioma Omagua. Berkeley: University of California, Department of Linguistics.

Oro, Ari Pedro

1989 Na Amazonia un Messias de Indios e Brancos: Traços para uma Antropologia do Messianismo. Petrópolis: Editora Vozes, Porto Alegre: Editora da Pontificia Universidade Católica do Rio Grande do Sul.

Pals, Daniel L.

1996 Seven Theories of Religion. Oxford University Press.

Pereira de Queiros, María Isaura

1969 Historia y Etnología de los Movimientos Mesiánicos. México, D.F.: Siglo XXI Editores.

Regan, Jaime

1977 Estudio de la Religiosidad Popular en la Amazonía. Iquitos: Coordinación Pastoral Regional de la Selva.

Regan, Jaime

1983 Hacia la Tierra Sin Mal, $1^{\text {a }}$ edición, 2 tomos. Iquitos: Centro de Estudios Teológicos de la Amazonía. 
Ribeiro, Darcy

1992 Indianidades y Venutopias. Buenos Aires: Ediciones del Sol.

Schaden, Egon

1974 Aspectos fundamentais da cultura guaraní. Universidade de Sao Paulo.

Vallejo Yopán, Rosa y Rosa Amías Murayari

2015 Diccionario del Idioma Kukama-Kukamiria. Iquitos: FORMABIAP-ISEPLAIDESEP. 